\title{
Assessing species traits and landscape relationships of the mammalian carnivore community in a neotropical biological corridor
}

\author{
Lain E. Pardo $\operatorname{Vargas}^{1,2}$ (D) Michael V. Cove $^{3} \cdot$ \\ R. Manuel Spinola ${ }^{2} \cdot$ Juan Camilo de la $\mathrm{Cruz}^{2}$. \\ Joel C. Saenz ${ }^{2}$
}

Received: 29 July 2015/Revised: 16 March 2016/Accepted: 25 March 2016/

Published online: 6 April 2016

(C) Springer Science+Business Media Dordrecht 2016

\begin{abstract}
Mammalian carnivores play an important role in regulating food webs and ecosystems. While many carnivore populations are facing various threats such as habitat loss and fragmentation, poaching, and illegal trade, others have adapted to human-dominated landscapes. Information about Neotropical carnivore communities in particular is limited, especially in disturbed landscapes. We conducted a camera trap survey at 38 sites across the San Juan-La Selva Biological Corridor in Costa Rica to assess occupancy and detection probabilities of the carnivore community. We developed hypotheses within a likelihood-based framework in order to determine the landscape features and species traits (diet and size) that influenced their occupancy. We detected nine of the 13 native carnivores predicted to occur in the corridor. When modeled separately, each species responded to land cover changes differently, suggesting no strong community-wide predictors of occupancy. We then modeled three separate guilds within the carnivore community: omnivorous mesopredators, obligate carnivorous mesopredators, and apex predators. These community guild models revealed a negative relationship between omnivorous mesopredators and increasing forest and tree plantation cover, suggesting omnivores utilize forest fragments and edge habitats in agricultural landscapes. Obligate carnivorous mesopredator models did not reveal any strong habitat relationships, but landscape effects tended to contradict our a priori predictions. Apex predators were positively associated
\end{abstract}

Communicated by Dirk Sven Schmeller.

Electronic supplementary material The online version of this article (doi:10.1007/s10531-016-1089-7) contains supplementary material, which is available to authorized users.

Lain E. Pardo Vargas

lepardov@gmail.com; lainefren.pardovargas@my.jcu.edu.au

1 Centre for Tropical Environmental and Sustainability Science (TESS), College of Marine and Environmental Sciences, James Cook University, PO Box 6811, Cairns, QLD 4878, Australia

2 Instituto Internacional en Conservación y Manejo de Vida Silvestre, Universidad Nacional, Apartado, Heredia 1350-3000, Costa Rica

3 Department of Applied Ecology, North Carolina State University, Raleigh, NC 27695, USA 
with increasing forest and tree plantation cover, protected areas, and increasing distances to villages. Alarmingly, apex predators and obligate carnivorous mesopredators were generally rare within the biological corridor. A lack of top-down control alone might result in heightened occupancy for all mesopredators, but because the community is dominated by omnivorous species, bottom-up release from human-induced land cover changes and resource provision may better explain their high occupancy.

Keywords Biological corridor - Camera traps - Carnivores · Occupancy models · Omnivores · Mesopredators

\section{Introduction}

Mammalian species are important taxa given their role in natural ecosystems, participating in seed dispersal, pollination, and predation (Terborgh 1992). As for large carnivores, they typically regulate other mammalian and vertebrate populations, influencing the composition and structure of forests via trophic cascades (Terborgh 1988). These cascades may also regulate fire dynamics, reduce the spread of diseases, increase carbon sequestration, and prevent invasive species colonization (Estes et al. 2011). However, mammal communities remain one of the most vulnerable to habitat loss, fragmentation, poaching, and wildlife trafficking (Schipper et al. 2008). Species traits, particularly diet selection and size, likely play a role in carnivore vulnerability. Large carnivores are particularly vulnerable to local extinction due to their expansive space requirements at low population densities, long gestation, high parental investments, and direct persecution by, and competition with, humans (Noss et al. 1996; Woodroffe and Ginsberg 1998; Cardillo et al. 2004; Crooks 2002). However, some carnivores are able to occupy human-dominated landscapes (e.g. Crooks 2002, Pardo and Payán 2015). For instance, it has been suggested that omnivory (feeding at multiple trophic levels) allows some mesopredators to utilize human-derived resources (Cove et al. 2013). Notably, existing food web model predictions posit that omnivory should be rare in stable communities (Layman et al. 2015).

Protected areas have proven to be effective for the conservation of mammalian biodiversity (Bruner et al. 2001; Ahumada et al. 2011), but the majority of lands in biodiversity hotspots are not protected and are typically made up of heterogeneous landscapes with variable land uses (Myers et al. 2000). Biological corridors are often conceptualized and managed in an effort to maintain connectivity among protected areas, but there remains limited evidence of the effectiveness of these strategies for the conservation of entire carnivore communities (Rosenberg et al. 1997; Thornton et al. 2015). The majority of previous research has focused on large carnivores such as jaguars (Panthera onca) and pumas (Puma concolor) in protected areas or reserves (Carrillo et al. 2009; Salom-Pérez et al. 2007), and therefore there is a need for further examination of the remainder of the carnivore community, particularly mesopredators. Costa Rica contains portions the Mesoamerican Biological Corridor and with a relatively speciose carnivore community (21 terrestrial species representing five families; Rodríguez-Herrera et al. 2002), the country provides a landscape well suited to study carnivore community dynamics in protected areas and their corridors.

The past decade of carnivore research has been influenced by the applications of two important techniques to assess mammalian conservation status and monitoring programs: 
camera traps and occupancy dynamics. Camera trapping is one of the most efficient tools for the study of rare and elusive terrestrial mammals (Maffei et al. 2002; Tobler et al. $2008)$. Occupancy $(\psi)$ can be interpreted as the probability that a site is occupied by a particular species, and the analysis is likelihood-based, with data derived from detection/ non-detection (camera) surveys (MacKenzie et al. 2002). Our objective was to estimate the influences of landscape attributes on the occupancy of a carnivore community based on a camera trapping survey across a biological corridor in northeastern Costa Rica. Furthermore, we aimed to examine how species traits, particularly their guild membership (omnivores, carnivores, apex predators), affected carnivore community occupancy.

\section{Materials and methods}

\section{Study area}

The San Juan-La Selva Biological Corridor (SJLSBC-2425 $\mathrm{km}^{2}$ ) is the only link between the Indio-Maíz Biological Reserve of southeastern Nicaragua, the lowland rainforest ecosystems of northern Costa Rica, and the Braulio Carrillo National Park among other Montane Forests in central Costa Rica into Panama. The corridor contains multiple land covers, including well-conserved primary forest, secondary vegetation (including tree plantations), and agricultural plantations (Chassot and Monge 2002). The majority of the land is privately owned, and subsistence agriculture is commonly interspersed amongst small reserves and lodges. Large-scale cattle ranches and monoculture plantations are also prevalent in the corridor and the surrounding landscape, especially in its southern extent, where pineapple is the dominant crop (Fagan et al. 2013). The corridor also contains an important protected area in the Maquenque Mixed-Use National Wildlife Refuge $\left(540 \mathrm{~km}^{2}\right)$.

\section{Survey design}

We conducted a camera-trapping survey of medium and large mammals at 38 forest sites within and surrounding the SJLSBC from June 2009 to July 2011 (Fig. 1; Appendix 3). We selected these sites to be representative of the dominant land-cover matrices within and surrounding the corridor (Cove et al. 2013). All forest sites were located on private land and consisted of eco-lodge forest reserves, tree plantations, managed forests, cattle ranches or agricultural plantations. We attempted to ensure independence among sites by spacing the camera-trap locations a minimum of $2 \mathrm{~km}$ apart. Although sites were sampled over a 2-year timeframe, these data do not violate any of the assumptions of the occupancy models (MacKenzie et al. 2002), particularly since the climate is relatively constant throughout the year, and the territorial nature of most carnivores reduces any seasonal effects due to migration across sites within the corridor.

We deployed a variable number (range $=4-10$ ) of camera stations at each site, spaced $250 \mathrm{~m}$ apart in different trap array configurations at each site (i.e. rectangular or triangular in shape) and, based on evidence of use by animals, placed the cameras along game trails or gaps in order to increase detections. Cove et al. (2013) observed no difference in detectability among the mammal community as a function of the number of cameras (4 vs. 6) at a site, but we extended upon that and examined detectability with additional cameras. Additionally, we used sardines as an olfactory attractant secured to a tree at a prudent 


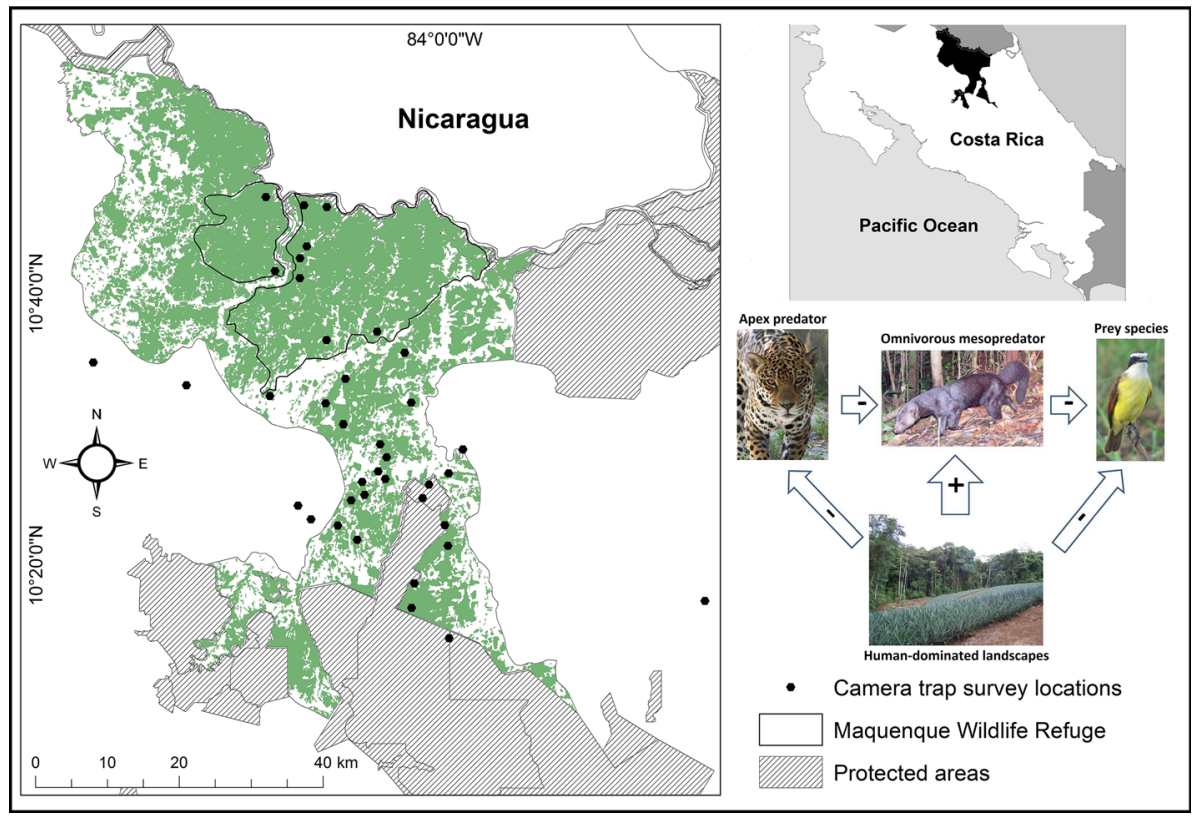

Fig. 1 Map of San Juan-La Selva Biological Corridor, Costa Rica, including forest cover in green color (primary, secondary, and tree plantations), protected areas, and the Maquenque Wildlife Refuge. The inset diagram shows the apparent relationships among habitat, apex predators, omnivorous mesopredators, and prey species. Map modified from Cove et al. (2014a, b)

distance in front of the camera. We avoided trails with high human use because of the potential theft of equipment. Since felids commonly use human trails, we also utilized felid-specific attractants (visual and olfactory) in an effort to increase detections along the sampled game trails at some of the cameras at a portion of the sites (Cove et al. 2014a, b). However, felid attractants did not increase overall detection rates of felids, so the data were pooled from all cameras with and without these attractants at a site for analyses.

We used infrared cameras (Scout Guard SG550, HCO Outdoor Products, Norcross, USA) or traditional flash cameras (Stealth Cam Sniper Pro Camera 57983, Stealth Cam LLC, Grand Prairie, USA). Cameras were operational at each site for 14-38 days, and were checked weekly or as often as was logistically possible. We calculated sampling effort (camera days) as the number of survey days multiplied by the number of cameras used at each site (Tobler et al. 2008). The use of a variable number of cameras, malfunctions, and some theft led to varying numbers of camera days per site, which we accounted for in our analysis.

\section{Site landscape covariates and analysis}

To determine landscape covariates, we created a $1 \mathrm{~km}$ radius buffer around a central point among the cameras to measure landscape features using a land-use/land-cover map (Atlas digital de Costa Rica 2008-ITCR) in Arcview GIS v3.3 (Environmental System Research Institute, USA). We selected 6 covariates a priori (Table 1) based on the known ecology of carnivores and the factors that could plausibly affect their occupancy and detectability 
Table 1 Site covariate descriptions and expected relationships based on data from camera-trap surveys in the San Juan-La Selva Biological Corridor, Costa Rica (2009-2011)

\begin{tabular}{|c|c|c|c|}
\hline Covariate & Code & Description & Prediction over occupancy \\
\hline Forest cover & for & $\begin{array}{l}\text { Percentage of forest (including } \\
\text { secondary vegetation) }\end{array}$ & $\begin{array}{l}\text { Increases in forest cover favors } \\
\text { occupancy }(\beta 1>0) \text {. }\end{array}$ \\
\hline $\begin{array}{l}\text { Forestry } \\
\text { plantations }\end{array}$ & plant & $\begin{array}{l}\text { Percentage of forest plantations (for } \\
\text { wood) }\end{array}$ & $\begin{array}{l}\text { As percentage of plantations increase } \\
\text { occupancy decreases }(\beta 1<0) \text {. }\end{array}$ \\
\hline $\begin{array}{l}\text { Distance to } \\
\text { villages }\end{array}$ & vil & $\begin{array}{l}\text { Linear distance to closest village or } \\
\text { settlement }(\mathrm{km})\end{array}$ & $\begin{array}{l}\text { As distance to village increases, } \\
\text { probability of occupancy increases as } \\
\text { well }(\beta 1>0) \text {. }\end{array}$ \\
\hline $\begin{array}{l}\text { Proximity to } \\
\text { protected } \\
\text { áreas }\end{array}$ & prot & $\begin{array}{l}\text { Categorical term that indicates the } \\
\text { proximity to the Maquenque Wildlife } \\
\text { Refuge or Braulio Carrillo National } \\
\text { park }(1=\text { within } 5 \mathrm{~km}, 0=\text { beyond } \\
5 \mathrm{~km})\end{array}$ & $\begin{array}{l}\text { Sites occurring in protected area buffers } \\
\text { will exhibit higher occupancy } \\
(\beta 1>0) \text {. }\end{array}$ \\
\hline Roads & road & $\begin{array}{l}\text { Density of roads in terms of total } \mathrm{km} \text { of } \\
\text { road within the buffer }\end{array}$ & $\begin{array}{l}\text { As density of roads increases, } \\
\text { occupancy would be affected } \\
\text { negatively }(\beta 1<0) \text {. }\end{array}$ \\
\hline Heterogeneity & het & Total land use types & $\begin{array}{l}\text { The more different land uses exist, the } \\
\text { probability of occupancy is higher in } \\
\text { most carnivores }(\beta 1>0) \text { (e.g. tayra, } \\
\text { coati) }\end{array}$ \\
\hline
\end{tabular}

Land uses considered: natural forest, no forest (e.g. agriculture or cattle), forest plantations, deforested area, water (Atlas 2008, FONAFIFO, Costa Rica)

(Cove et al. 2013; Wainwright 2002). The percentage of forest cover was measured as an index of connectivity and patch size due to its perceived importance for maintenance of biodiversity (e.g. Murcia 1995; Laurance et al. 2002). Since tree plantations are utilized by other large mammals (Schank et al. 2015), we also measured the percent cover of forest plantations within the buffer to explore the influence of reforestation and non-native trees on carnivore occupancy.

Because protected areas likely play a role in the distribution of carnivores (Ahumada et al. 2011), we used a binary covariate (protected $=1$, not protected $=0$ ) for sites occurring in the two major protected areas (i.e. Braulio Carrillo National Park or Maquenque National Wildlife Refuge) and within a $5 \mathrm{~km}$ buffer zone adjacent to their boundaries. Although a continuous covariate could be used for sites outside of the protected areas, a categorical value is better suited because sites within the protected areas would all receive the same value. It is also probable that settlements and high-density human population increase the risk of extinction for some carnivores, so distance to the closest village was used as a proxy for human presence and/or disturbance (e.g. Cardillo et al. 2004). Density of roads was selected as an index of fragmentation and penetrability from the effect of roads (Haddad 2015). Finally, the count of different cover types in the buffer served as a proxy for habitat heterogeneity, which has also been shown to influence occupancy of certain species (e.g. Cove et al. 2013; Crooks 2002). Tables 1 and 2 show the covariates evaluated, and their associated prediction for occupancy models and for detection probabilities. 
Table 2 Detection covariates description and expected relationship based on data from camera-trap surveys in the San Juan-La Selva Biological Corridor, Costa Rica (2009-2011)

\begin{tabular}{llll}
\hline Covariate & Code & Description & Prediction on $\mathrm{p}$ \\
\hline Forest & for & $\begin{array}{c}\text { Percentage of Forest (including } \\
\text { secondary vegetation) }\end{array}$ & $\begin{array}{c}\text { As forest cover increases, detection probability } \\
\text { would be reduced }(\beta 1<0) .\end{array}$ \\
Days & days & $\begin{array}{c}\text { Total number of days in which } \\
\text { cameras were active in the site }\end{array}$ & $\begin{array}{c}\text { The more days cameras are active the greater } \\
\text { detection probability }(\beta 1>0) .\end{array}$ \\
Cameras & cams & $\begin{array}{c}\text { Total number of cameras used in the } \\
\text { suerveys }(4,6,8)\end{array}$ & $\begin{array}{c}\text { Detection probability increases as more } \\
\text { cameras are used }(\beta 1>0) .\end{array}$ \\
\hline
\end{tabular}

\section{Occupancy}

We employed the classic single-season occupancy models developed by MacKenzie et al. $(2002,2006)$ to determine the occupancy of carnivores while accounting for detection bias. Although there are multi-season occupancy models (MacKenzie et al. 2006), we only sampled each site during a single season, which meets the assumptions of the single season model and also ensures independence among sites (Cove et al. 2013). We compiled the photographs into detection histories consisting of seven occasions, each of which was formed by the combination of five camera days per survey. In each model, site occupancy $(\Psi)$ and detectability (p) were modeled as a constant or a function of the different covariate combinations [e.g. $\Psi$ (covariate), p(constant); $\Psi$ (constant), p(covariate), as well as additive models (e.g. $\Psi($ covariate + covariate), p(constant)]. We implemented the models in Presence 3.1 (Hines 2006), with all continuous covariates standardized to $z$ scores.

We used the Akaike Information Criterion (AIC) to rank 15 a priori models (Appendix 1). All models contained within the $90 \%$ confidence set (cumulative Akaike weight, $\left.\Sigma \omega_{i}>0.90\right)$ were considered to have substantial support as the top-ranking models (Burnham and Anderson 2002). We determined the most influential variables in the occupancy models by summing Akaike weights of models containing each variable and if parameter confidence intervals excluded zero. Although the values for occupancy and detection probability are site-dependent, we present the mean values $(\hat{\Psi}$ and $\hat{p})$ for each model following Linkie et al. (2007). We also assessed the accuracy of each model using the formula $(\mathrm{SE} / \hat{\Psi}) \times 100$, where $\hat{\Psi}=$ estimated mean occupancy for a given model; $\mathrm{SE}=$ its associated standard error. A model is considered to have adequate accuracy when this value is below $30 \%$ (Linkie et al. 2007). When Akaike weights were difficult to interpret given their similar values, we also model averaged occupancy from multiple models. For this we used the Burnham and Anderson (2002) equation as follows (see also MacKenzie et al. 2006):

$$
\begin{gathered}
\hat{\theta}_{A}=\sum_{l=1}^{m} \omega_{i} \hat{\theta}_{l} \\
\text { S.E. }\left(\hat{\theta}_{A}\right)=\sum_{l=1}^{m} \omega_{i} \sqrt{\operatorname{Var}\left(\hat{\theta}_{l} \mid M_{l}\right)+\left(\hat{\theta}_{l}-\hat{\theta}_{A}\right)^{2}}
\end{gathered}
$$

where $\omega_{i}=$ Akaike weight and $\hat{\theta}_{l}=$ individual mean occupancy estimate for each model.

Since some species went undetected, some species were rarely detected, and some were common, we also modeled all 13 species within three guild occupancy models in which we 
extended the classic models and borrowed information from the more commonly detected species to make inferences about the undetected species (Mackenzie et al. 2006, RuizGutiérrez et al. 2010). We accounted for trait variation among the different trophic levels within the carnivore community by analyzing three separate guilds that we a priori identified as important: omnivorous mesopredators, obligate carnivorous mesopredators, and apex predators. The definitions of apex predators and mesopredators could be relative and to an extent context-dependent (Ritchie and Johnson 2009). Therefore, we use the following criteria to classify the carnivore community assessed in this research. An apex predator is a species that occupies the top trophic position and is generally a large-sized predator $(>\sim 50 \mathrm{~kg})$. Mesopredators, in turn, are species below the top trophic position, and are usually mid-sized mammals ( $\sim 3.5$ to $15 \mathrm{~kg}$ ). Omnivory is used for species that consume resources or prey at multiple trophic levels (i.e. they consume plant, fruits, vertebrate or invertebrate animals, human waste, etc.), while obligate carnivores are restricted to animal prey. The omnivores include five species [common raccoon (Procyon lotor), white-nosed coati (Nasua narica), tayra (Eira Barbara), striped hog-nosed skunk (Conepatus semistriatus), coyote (Canis latrans)] from four families (e.g. Procyonidae, Mustelidae, Mephitidae, and Canidae). The obligate carnivorous mesopredators include six species [grison (Galictis vittata), long-tailed weasel (Mustela frenata), Neotropical river otter (Lutra longicaudis), margay (Leopardus wiedii), ocelot (Leopardus pardalis), and jaguarundi (Puma yagouarondi)]. The apex predators are the large felids [jaguar (Panthera onca) and puma (Puma concolor)].

Dividing up the carnivore community based on guild traits allowed us to determine the effects of habitat characteristics on individual guilds to provide more robust parameter estimates and derived parameters compared to single-species models, including conditional occupancy estimates for species that were never detected. Model characteristics and selection were the same as those presented earlier for the single species models, except we modeled the guilds in the carnivore community with constant detection, since there was no clear trend on detection from the single species models. We considered models within the $90 \%$ confidence set to have strong support for predicting the habitat relationships.

\section{Results}

Our sampling effort consisted of a total of 6356 camera days with an average of 167.26 $( \pm 59.12 \mathrm{SE})$ per site. We detected nine terrestrial carnivores in SJLS Biological Corridor: common raccoon, white-nosed coati, tayra, grison, striped hog-nosed skunk, coyote, ocelot, margay, and puma. We did not detect the other apex predator (jaguar) during the surveys. No carnivores were detected at two of the sites. Although nine species were detected across the entire corridor, the average number detected per site was only 2.47 ( $\pm 0.23 \mathrm{SE})$ species.

Three of the species (grison, margay, and coyote) were too sparsely detected to analyze within single species models. No single model emerged as the top-ranking model (i.e. $\omega_{i}>0.90$ ) for any of the other species (Table 3). Alternatively, most of the models for the majority of species had low $\triangle \mathrm{AIC}$ values between models. The top-ranking occupancy models for raccoons, coatis, and hog-nosed skunks were the constant (.) models. Forest cover was included as a covariate in the $90 \%$ confidence sets with a negative relationship between increasing forest and occupancy for each of these omnivores (Table 3). Similarly, the top-ranking tayra models contained forest $\left(\Sigma \omega_{i}=0.47\right)$ and tree plantation cover 
Table 3 Model selection statistics, mean and model averaged occupancy $(\hat{\Psi})$ detection probability $(\hat{p})$ and covariate directions $(\beta)$ for carnivores in San Juan-La Selva Biological Corridor, Costa Rica (2009-2011)

\begin{tabular}{|c|c|c|c|c|c|c|c|c|c|c|}
\hline Model & $\Delta \mathrm{AIC}$ & $\omega i$ & $\mathrm{k}$ & $-2 \log (£)$ & $\hat{\Psi}$ & $\mathrm{SE}$ & $\hat{p}$ & SE & $\beta$ & Prec \\
\hline \multicolumn{11}{|l|}{ Racoon } \\
\hline$\Psi(),. \mathrm{p}$ (for) & 0.00 & 0.37 & 3 & 79.26 & 0.64 & 0.20 & 0.10 & 0.03 & & 31.64 \\
\hline$\Psi($ for $), \mathrm{p}($ for $)$ & 0.52 & 0.28 & 4 & 77.78 & 0.26 & 0.16 & 0.14 & 0.08 & - & 60.76 \\
\hline$\Psi($ for $), \mathrm{p}()$. & 2.03 & 0.13 & 3 & 81.29 & 0.20 & 0.07 & 0.34 & 0.08 & - & 36.91 \\
\hline$\Psi($ for + plant $), p()$. & 2.89 & 0.09 & 4 & 80.15 & 0.20 & 0.08 & 0.35 & 0.76 &,-- & 41.32 \\
\hline$\Psi($ Model averaged $)$ & & & & & 0.35 & 0.25 & & & & \\
\hline \multicolumn{11}{|l|}{ White-nosed coati } \\
\hline$\Psi(),. \mathrm{p}()$. & 0.00 & 0.15 & 2 & 216.58 & 0.62 & 0.09 & 0.42 & 0.05 & & 14.06 \\
\hline$\Psi(),. \mathrm{p}(\mathrm{cams})$ & 0.14 & 0.14 & 3 & 214.72 & 0.63 & 0.09 & 0.42 & 0.06 & & 14.12 \\
\hline$\Psi($ for $), \mathrm{p}()$. & 1.19 & 0.08 & 3 & 215.77 & 0.62 & 0.12 & 0.43 & 0.05 & - & 18.74 \\
\hline$\Psi$ (for), $\mathrm{p}$ (cams) & 1.32 & 0.08 & 4 & 213.90 & 0.63 & 0.12 & 0.43 & 0.06 & - & 18.76 \\
\hline$\Psi($ prot $), \mathrm{p}()$. & 1.50 & 0.07 & 3 & 216.08 & 0.63 & 0.12 & 0.42 & 0.05 & - & 19.31 \\
\hline$\Psi(),. \mathrm{p}$ (days) & 1.60 & 0.07 & 3 & 216.18 & 0.62 & 0.09 & 0.44 & 0.07 & & 14.16 \\
\hline$\Psi($ road $), \mathrm{p}()$. & 1.61 & 0.07 & 3 & 216.19 & 0.63 & 0.12 & 0.42 & 0.05 & - & 19.28 \\
\hline$\Psi($ plant $), \mathrm{p}()$. & 1.62 & 0.07 & 3 & 216.20 & 0.62 & 0.11 & 0.43 & 0.05 & + & 17.14 \\
\hline$\Psi($ vil $), \mathrm{p}()$. & 1.72 & 0.06 & 3 & 216.30 & 0.63 & 0.12 & 0.42 & 0.05 & + & 19.28 \\
\hline$\Psi($ het $), \mathrm{p}()$. & 1.81 & 0.06 & 3 & 216.39 & 0.62 & 0.11 & 0.43 & 0.05 & + & 18.27 \\
\hline$\Psi(),. \mathrm{p}$ (for) & 2.00 & 0.06 & 3 & 216.58 & 0.62 & 0.09 & 0.43 & 0.07 & & 14.16 \\
\hline$\Psi($ Model averaged $)$ & & & & & 0.55 & 0.17 & & & & \\
\hline \multicolumn{11}{|l|}{ Tayra } \\
\hline$\Psi($ for + plant $), \mathrm{p}()$. & 0.00 & 0.26 & 4 & 192.40 & 0.73 & 0.14 & 0.26 & 0.04 &,-- & 19.70 \\
\hline $\begin{array}{l}\Psi(\text { for }+ \text { plant }) \\
\text { p(days })\end{array}$ & 0.95 & 0.16 & 5 & 191.35 & 0.75 & 0.18 & 0.06 & 0.15 &,-- & 24.24 \\
\hline$\Psi($ plant $), \mathrm{p}()$. & 1.90 & 0.10 & 3 & 196.30 & 0.77 & 0.14 & 0.25 & 0.05 & - & 18.23 \\
\hline$\Psi(),. \mathrm{p}($ days $)$ & 2.27 & 0.08 & 3 & 196.67 & 0.76 & 0.10 & 0.25 & 0.06 & & 13.68 \\
\hline$\Psi(),. \mathrm{p}($ for $)$ & 2.51 & 0.07 & 3 & 196.91 & 0.79 & 0.12 & 0.24 & 0.06 & & 14.97 \\
\hline$\Psi(),. \mathrm{p}()$. & 2.65 & 0.07 & 2 & 199.05 & 0.75 & 0.12 & 0.26 & 0.05 & & 15.66 \\
\hline$\Psi($ for $), \mathrm{p}()$. & 3.16 & 0.05 & 3 & 197.56 & 0.72 & 0.15 & 0.26 & 0.05 & - & 21.11 \\
\hline$\Psi(),. \mathrm{p}(\mathrm{cams})$ & 3.33 & 0.05 & 3 & 197.73 & 0.84 & 0.18 & 0.23 & 0.06 & & 20.85 \\
\hline$\Psi($ prot $), \mathrm{p}()$. & 3.87 & 0.04 & 3 & 198.27 & 0.75 & 0.15 & 0.26 & 0.05 & - & 20.27 \\
\hline$\Psi($ het $), \mathrm{p}()$. & 4.14 & 0.03 & 3 & 198.54 & 0.73 & 0.14 & 0.26 & 0.05 & + & 19.01 \\
\hline$\Psi($ Model averaged $)$ & & & & & 0.68 & 0.24 & & & & \\
\hline \multicolumn{11}{|c|}{ Striped hog-nosed skunk } \\
\hline$\Psi(),. \mathrm{p}($ for $)$ & 0.00 & 0.24 & 3 & 61.95 & 0.59 & 0.38 & 0.06 & 0.05 & & 64.74 \\
\hline$\Psi(),. \mathrm{p}()$. & 1.61 & 0.10 & 2 & 65.56 & 0.34 & 0.21 & 0.11 & 0.07 & & 59.94 \\
\hline$\Psi($ for $), \mathrm{p}$ (for) & 1.99 & 0.09 & 4 & 61.94 & 0.61 & 0.52 & 0.06 & 0.05 & + & 84.12 \\
\hline$\Psi($ for $), \mathrm{p}()$. & 2.12 & 0.08 & 3 & 64.07 & 0.30 & 0.19 & 0.12 & 0.07 & - & 63.79 \\
\hline$\Psi(),. \mathrm{p}($ days $)$ & 2.18 & 0.08 & 3 & 64.13 & 0.36 & 0.20 & 0.10 & 0.07 & & 53.93 \\
\hline$\Psi(),. \mathrm{p}(\mathrm{cams})$ & 2.20 & 0.08 & 3 & 64.15 & 0.42 & 0.23 & 0.10 & 0.07 & & 55.57 \\
\hline$\Psi($ vil $), \mathrm{p}()$. & 2.59 & 0.06 & 3 & 64.54 & 0.35 & 0.24 & 0.11 & 0.07 & - & 69.88 \\
\hline$\Psi(\operatorname{road}), \mathrm{p}()$. & 3.49 & 0.04 & 3 & 65.44 & 0.33 & 0.23 & 0.11 & 0.07 & + & 67.97 \\
\hline$\Psi($ het $), \mathrm{p}()$. & 3.49 & 0.04 & 3 & 65.44 & 0.34 & 0.24 & 0.11 & 0.07 & + & 70.09 \\
\hline
\end{tabular}


Table 3 continued

\begin{tabular}{|c|c|c|c|c|c|c|c|c|c|c|}
\hline Model & $\Delta \mathrm{AIC}$ & $\omega i$ & $\mathrm{k}$ & $-2 \log (\mathfrak{f})$ & $\hat{\Psi}$ & SE & $\hat{p}$ & SE & $\beta$ & Prec \\
\hline$\Psi($ plant $), \mathrm{p}()$. & 3.58 & 0.04 & 3 & 65.53 & 0.34 & 0.23 & 0.11 & 0.07 & - & 67.71 \\
\hline$\Psi($ prot $), \mathrm{p}()$. & 3.58 & 0.04 & 3 & 65.53 & 0.34 & 0.24 & 0.11 & 0.07 & + & 70.37 \\
\hline$\Psi($ for + vil $), \mathrm{p}()$. & 3.60 & 0.04 & 4 & 63.55 & 0.30 & 0.21 & 0.13 & 0.07 &,-- & 70.88 \\
\hline$\Psi($ Model averaged $)$ & & & & & 0.40 & 0.31 & & & & \\
\hline \multicolumn{11}{|l|}{ Ocelot } \\
\hline$\Psi($ vil), $\mathrm{p}$ (days) & 0.00 & 0.28 & 4 & 192.11 & 0.76 & 0.15 & 0.29 & 0.06 & - & 19.26 \\
\hline$\Psi($ vil $), \mathrm{p}()$. & 1.34 & 0.14 & 3 & 195.45 & 0.71 & 0.12 & 0.29 & 0.05 & - & 16.97 \\
\hline$\Psi($ het $), \mathrm{p}()$. & 2.34 & 0.09 & 3 & 196.45 & 0.71 & 0.13 & 0.29 & 0.05 & + & 17.91 \\
\hline$\Psi(),. \mathrm{p}$ (days) & 2.35 & 0.09 & 3 & 196.46 & 0.74 & 0.11 & 0.29 & 0.07 & & 15.16 \\
\hline$\Psi(),. \mathrm{p}$ (for) & 2.53 & 0.08 & 3 & 196.64 & 0.70 & 0.10 & 0.31 & 0.07 & & 13.77 \\
\hline$\Psi(),. \mathrm{p}()$. & 3.15 & 0.06 & 2 & 199.26 & 0.72 & 0.10 & 0.29 & 0.05 & & 14.34 \\
\hline$\Psi($ for + vil $), \mathrm{p}()$. & 3.20 & 0.06 & 4 & 195.31 & 0.72 & 0.17 & 0.28 & 0.05 &,+- & 23.43 \\
\hline$\Psi($ plant $), \mathrm{p}()$. & 3.47 & 0.05 & 3 & 197.58 & 0.73 & 0.13 & 0.28 & 0.05 & - & 17.28 \\
\hline$\Psi($ for + het $), \mathrm{p}()$. & 3.70 & 0.04 & 4 & 195.81 & 0.73 & 0.17 & 0.28 & 0.05 &,++ & 22.77 \\
\hline$\Psi($ for + plant $), \mathrm{p}()$. & 4.80 & 0.03 & 4 & 196.91 & 0.73 & 0.17 & 0.28 & 0.05 &,-- & 23.98 \\
\hline$\Psi($ Model averaged $)$ & & & & & 0.67 & 0.22 & & & & \\
\hline \multicolumn{11}{|l|}{ Puma } \\
\hline$\Psi($ plant $), \mathrm{p}()$. & 0.00 & 0.29 & 3 & 39.66 & 0.16 & 0.12 & 0.15 & 0.09 & + & 72.35 \\
\hline$\Psi($ plant $), \mathrm{p}($ cams $)$ & 0.07 & 0.28 & 4 & 37.73 & 0.18 & 0.11 & 0.16 & 0.11 & + & 61.96 \\
\hline$\Psi($ for + plant $), \mathrm{p}()$. & 0.63 & 0.21 & 4 & 38.29 & 0.21 & 0.15 & 0.12 & 0.07 &,++ & 73.01 \\
\hline$\Psi(),. \mathrm{p}()$. & 3.72 & 0.05 & 2 & 45.38 & 0.24 & 0.20 & 0.10 & 0.09 & & 82.65 \\
\hline$\Psi(),. \mathrm{p}(\mathrm{cams})$ & 4.28 & 0.03 & 3 & 43.94 & 0.23 & 0.15 & 0.13 & 0.12 & & 64.76 \\
\hline$\Psi($ vil $), p()$. & 4.60 & 0.03 & 3 & 44.26 & 0.21 & 0.17 & 0.12 & 0.09 & + & 80.19 \\
\hline$\Psi($ het $), \mathrm{p}()$. & 5.26 & 0.02 & 3 & 44.92 & 0.23 & 0.22 & 0.10 & 0.09 & + & 94.17 \\
\hline$\Psi($ Model averaged $)$ & & & & & 0.17 & 0.34 & & & & \\
\hline
\end{tabular}

$\triangle A I C$ difference in AIC values between each model with the lowest AIC mode (best model), wi Akaike weight, $k$ number of parameters in the model, $-2 \log (£)-2 * \log$-likelihood, $S E$ standard error, Prec estimated precision. All models presented represent $90 \%$ of the total Akaike weight

$\left(\Sigma \omega_{i}=0.52\right)$, also with negative relationships between increasing forest cover and occupancy.

Distance to the closest village was the most important covariate only for ocelot models $\left(\Sigma \omega_{i}=0.42\right)$, presenting a negative relationship between increasing distance and ocelot occupancy. Forest plantation cover was the most important covariate for puma $\left(\Sigma \omega_{i}=0.77\right)$, followed by forest cover $\left(\Sigma \omega_{i}=0.24\right)$, both presenting positive relationships between increasing cover and puma occupancy. The proximity to protected areas and road covariates did not receive strong support for any of the single-species models.

The untransformed beta coefficients from the single species models did not often correspond with our a priori predictions. In particular, forest cover had a negative relationship with all detected carnivores except the felids, but none of the relationships were significant because the estimate confidence intervals included zero (Appendix 2). Detection probabilities were variable among species, with hog-nosed skunk exhibiting the lowest detection probability $(0.06 \pm 0.05 \mathrm{SE})$ and coati exhibiting the greatest $(0.42 \pm 0.05 \mathrm{SE})$. The variables that influence detectability were different for each species. However, for each one 
there was at least one model that includes a variable influencing detection probability within the top models $(\triangle \mathrm{AIC}<2)$. Forest cover had an effect on the probability of detection for several of the detected species (Table 3). The effect of the number of cameras had support from data for the models of puma and coati, suggesting this variable also influences their detection probabilities, but only weakly. Additionally, the total number of camera days was included in the best models for coati, ocelot, and tayra (Table 3).

The guild models revealed a strong positive relationship between omnivory and guild mean occupancy $(\hat{\Psi}=0.38 \pm 0.04 \mathrm{SE})$ for mesopredators, whereas models for mesopredators that were obligate carnivores suggested intermediate guild mean occupancy $(\hat{\Psi}=0.18 \pm 0.03 \mathrm{SE})$. Furthermore, there was a negative relationship between the apex predator guild and their mean occupancy $(\hat{\Psi}=0.12 \pm 0.10$ SE; Table 4$)$. Forest cover and plantation cover were contained in the top-ranking models and were negatively related to omnivore guild occupancy (Table 4), which was contrary to a priori predictions. Distance to nearest village, habitat heterogeneity, tree plantations, roads, forest cover, and protected areas were all contained in the top-ranking models for the obligate carnivore mesopredator models, but the beta coefficients were highly variable and did not correspond with a priori predictions, except for habitat heterogeneity (+; Table 4). The top-ranking

Table 4 Model selection statistics and estimated covariate effects $(\beta)$ for carnivore community occupancy models from camera trap surveys in and around the San Juan-La Selva Biological Corridor, Costa Rica, 2009-2011

\begin{tabular}{|c|c|c|c|c|c|c|c|c|}
\hline Model & $\Delta \mathrm{AIC}$ & $\omega i$ & $\mathrm{k}$ & $-2 \log (£)$ & $\beta 1$ & SE & $\beta 2$ & SE \\
\hline \multicolumn{9}{|l|}{ Mesopredators } \\
\hline \multicolumn{9}{|l|}{ Omnivores } \\
\hline$\Psi($ for + plant $), \mathrm{p}()$. & 0.00 & 0.64 & 4 & 656.88 & -0.72 & 0.19 & \multirow[t]{2}{*}{-0.33} & \multirow[t]{2}{*}{0.18} \\
\hline$\Psi($ for $), \mathrm{p}()$. & 1.34 & 0.33 & 3 & 660.22 & -0.61 & 0.18 & & \\
\hline \multicolumn{9}{|l|}{ Obligate carnivores } \\
\hline$\Psi($ vil $), \mathrm{p}()$. & 0.00 & 0.28 & 3 & 348.56 & -0.46 & 0.31 & & \\
\hline$\Psi(),. \mathrm{p}()$. & 0.62 & 0.20 & 2 & 351.18 & & & & \\
\hline$\Psi($ het $), \mathrm{p}()$. & 1.57 & 0.13 & 3 & 350.13 & 0.23 & 0.22 & & \\
\hline$\Psi($ plant $), \mathrm{p}()$. & 1.82 & 0.11 & 3 & 350.38 & -0.21 & 0.26 & & \\
\hline$\Psi(\operatorname{road}), \mathrm{p}()$. & 2.45 & 0.08 & 3 & 351.01 & 0.09 & 0.21 & & \\
\hline$\Psi($ for $), \mathrm{p}()$. & 2.61 & 0.08 & 3 & 351.17 & -0.02 & 0.21 & & \\
\hline$\Psi(\operatorname{prot}), \mathrm{p}()$. & 2.61 & 0.08 & 3 & 351.17 & -0.05 & 0.43 & & \\
\hline \multicolumn{9}{|l|}{ Apex predators } \\
\hline$\Psi($ plant $), \mathrm{p}()$. & 0.00 & 0.37 & 3 & 45.98 & 1.22 & 0.94 & \multirow{4}{*}{1.70} & \multirow{5}{*}{2.15} \\
\hline$\Psi($ for + plant $), \mathrm{p}()$. & 1.04 & 0.22 & 4 & 45.02 & 0.93 & 1.28 & & \\
\hline$\Psi($ prot $), \mathrm{p}()$. & 1.28 & 0.19 & 3 & 47.26 & 30.23 & 3.45 & & \\
\hline$\Psi(),. \mathrm{p}()$. & 3.15 & 0.08 & 2 & 51.13 & & & & \\
\hline$\Psi($ vil $), \mathrm{p}()$. & 3.90 & 0.05 & 3 & 49.88 & 0.53 & 0.47 & & \\
\hline
\end{tabular}

Occupancy $(\psi)$ was held constant (.) or varied as a function of trophic covariates and/or habitat covariates, probability of detection (p) was held constant (.)

$\triangle A I C$ difference in AIC values between each model with the lowest AIC mode (best model), wi Akaike weight, $k$ number of parameters in the model, $-2 \log (£)-2 * \log$-likelihood, $S E$ standard error. All models presented represent $90 \%$ of the total Akaike weight 
models for the apex predators included tree plantations, forest cover, protected areas, and distance to nearest village, and all of these were positive relationships, which corresponded with a priori predictions (Table 4).

\section{Discussion}

Our study represents a substantial camera trapping effort for the carnivore community within and across a biological corridor that is mostly privately owned patches of forest among a heterogeneous matrix of different land-uses. This differs from most camera trap studies in the Neotropics that focus survey efforts within protected areas (e.g. Tobler et al. 2008), which are not representative of the majority of the remaining habitat for carnivores. Although several obligate carnivorous mesopredators were detected (e.g. ocelot, margay, and grison), the majority of them were omnivorous (five species). We discuss two apparent mechanisms, top-down control and bottom-up release, contributing to the omnivoredominated carnivore community of the San Juan-La Selva Biological Corridor.

The presence of large carnivores is considered an important indicator of ecosystem integrity, suggesting relative maintenance of food webs (Noss et al. 1996). Our nondetection of jaguars and rare detection of pumas is cause for concern regarding the conservation status of these apex predators in the biological corridor. Although our camera methods were not large cat-specific, we utilized prey trails, some human trails, and attractants to better detect these large carnivores. Our results correspond with other monitoring programs that rarely detect jaguars ( $\sim 3$ camera detections in last decade) in the northern zone of Costa Rica (Corrales-Gutiérrez 2011). These top predators are often killed due to perceived threats to livestock, dogs, and people.

Through the disappearance of top-down control, the loss of large carnivores from many systems has facilitated the expansion and increasing abundance of mesopredators. Commonly termed the Mesopredator Release Hypothesis-MRH (Soulé et al. 1988; Cove et al. 2012a), it is probable that the high occupancy of mesopredators is facilitated by the apparent rarity of the large cats (jaguar and puma) at sites across the corridor. The recent colonization of the corridor by the coyote, a mesopredator typically suppressed by the apex predators, provides further evidence of top-down release (Cove et al. 2012b). We suggest that it is important to further examine the possible consequences of coyote range expansion in northeastern Costa Rica and further south. Coyote presence will generate novel interactions and could exert unpredictable impacts on local fauna through predation and indirect effects (Cove et al. 2012b).

Mesopredators are often generalist by nature and many are omnivorous, which allows them to supplement their diet with human-derived waste, refuse, and agricultural produce. Omnivory is a species trait that has allowed many of the carnivores in the community to respond well to land-cover changes and agricultural development (e.g. Bottom-up release-Cove et al. 2013). This is supported by our data because omnivorous mesopredators were negatively associated with increasing forest cover, suggesting that they utilize forest fragments and agricultural edge habitats. All five of the omnivorous mesopredators were commonly detected throughout the corridor, yet only half of the obligate carnivores were detected very rarely, aside from ocelots. A lack of top-down control alone might result in heightened occupancy for all mesopredators, but because the community is dominated by omnivorous species, bottom-up support from human-induced land cover changes and resource provision may better explain the high occupancy. In a protected 
reserve in Peru, Tobler et al. (2008) observed omnivorous mesopredators to be the least common group among the carnivore community, with apex predators being the most commonly detected species.

Mesopredator use of agricultural resources to supplement their diets is a common phenomenon in temperate zones (Elmhagen and Rushton 2007; Garrott et al. 1993; Roemer et al. 2009), yet we are unaware of any studies that have observed similar community dynamics in the Neotropics. Since omnivorous mesopredators can exist at heightened densities due to agricultural resources, their community effects warrant further exploration to predict ecosystem-level effects. The heightened occupancy of omnivores in the corridor is of concern because omnivory should not be common in stable communities (Layman et al. 2015).

The importance of forest and the negative effects of fragmentation to biodiversity have been largely assessed (e.g. Fahrig 2003; Michalski and Peres 2007; Pardini et al. 2005; Murcia 1995; Laurance et al. 2002). Forest cover was a strongly supported covariate influencing occupancy of the majority of species, but the relationship was negative for most of the species except the apex predators. These results should not be interpreted as suggesting that reduced natural forest corresponds with increasing carnivore occupancy but rather that the majority of the species persist regardless of the amount of forest cover because they are positively associated with human land uses (as discussed previously). The negative influence of forest cover could also be a result of detecting multiple individuals in small isolated forest sites, since some models suggested forest had a negative relationship with detection probabilities. Forest plantations and sustainably managed forest (low impact logging) have been observed to support wildlife conservation in other areas (e.g. Guariguata et al. 2002; Johns 1985; Pearce et al. 2003). Forest cover remains relatively high throughout the corridor so reduction in cover did not seem to pass below a threshold that would have negatively affected species occupancy, but it is probable that with reduced connectivity, the smaller forest fragments might carry a high extinction debt (Cove et al. 2013).

The biological corridor is a mixture of different land uses, but it still retains important forested areas that contribute to habitat for the carnivore community and the functionality of the system. Therefore, the value of private lands and the contribution of small forest remnants should not be underestimated in conservation, especially when they contribute to the connectivity of a biological corridor. However, it is important to continue investigating how small private forests can contribute to conservation, particularly in the face of expanding agricultural frontiers, paired with climate change and potential effects of future extinction debt and forest defaunation. Furthermore, we recommend continued monitoring of the occupancy of carnivore communities and call for multi-taxa studies to examine the possible ecosystem-wide effects of mesopredators in altered Neotropical environments.

Acknowledgments We thank all the field assistants and lodges that helped with logistics for this research. Special thanks to Panthera-Costa Rica, and the private reserves or farms that allowed us to work inside, to Jose Fernando Gonzalez-Maya for his comments and collaboration during the M.Sc. dissertation process of the first author and during the writing process of this manuscript. We are also grateful to anonymous reviewers for their relevant edits and suggestions on the manuscript. Funding for this research was provided by Universidad Nacional de Costa Rica, Instituto Internacional de Conservación y Manejo de Vida Silvestre (ICOMVIS). IDEA WILD also helped with some indispensable equipment. Research was also supported and permitted by the National System of Conservation Areas-Ministry of the Environment, Energy and Telecommunication. 


\section{References}

Ahumada JA, Silva CE, Gajapersad K, Hallam C, Hurtado J, Martin E, McWilliam A, Mugerwa B, O’Brien T, Rovero F, Sheil D (2011) Community structure and diversity of tropical forest mammals: data from a global camera trap network. Philos Trans R Soc B Biol Sci 366(1578):2703-2711

Bruner AG, Gullison RE, Rice RE, Fonseca GA (2001) Effectiveness of parks in protecting tropical biodiversity. Science 291:125-128

Burnham KP, Anderson DR (2002) Model selection and multimodel inference: a practical informationtheoretic approach. Springer, Berlin

Cardillo M, Purvis A, Sechrest W, Gittleman J, Bielby J, Mace G (2004) Human population density and extinction risk in the world's carnivores. PLoS Biol 2(7):909-914

Carrillo E, Fuller TK, Saenz JC (2009) Jaguar (Panthera onca) hunting activity: effects of prey distribution and availability. J Trop Ecol 25(05):563-567

Chassot O, Monge G (2002) Corredor Biológico San Juan-La Selva: Ficha técnica. Centro Científico Tropical, San José

Corrales-Gutiérrez D, Carazo-Salazar J, Salom Pérez R (2011) Validación de campo del Corredor Biológico San Juan-La Selva: evaluación de la presencia del Jaguar y sus principales presas. Informe técnico. Fundación Panthera, Costa Rica

Cove MV, Jones BM, Bossert AJ, Clever DR Jr, Dunwoody RK, White BC, Jackson VL (2012a) Use of camera traps to examine the mesopredator release hypothesis in a fragmented Midwestern landscape. Am Midl Nat 168(2):456-465

Cove MV, Pardo L, Spínola RM, Jackson VL, Saenz JC (2012b) Coyote Canis latrans (Carnivora: Canidae) range extension in northeastern Costa Rica: possible explanations and consequences. Latin Am J Conserv 3(1):82-86

Cove MV, Spínola RM, Jackson VL, Saenz JC, Chassot O (2013) Integrating occupancy modeling and camera-trap data to estimate medium and large mammal detection and richness in a Central American biological corridor. Trop Conserv Sci 6(6):781-795

Cove MV, Spinola RM, Jackson VL, Saenz JC (2014a) The role of fragmentation and landscape changes in the ecological release of common nest predators in the Neotropics. PeerJ 2:e464. doi:10.7717/peerj.464

Cove MV, Spinola RM, Jackson VL, Saenz JC (2014b) Camera trapping ocelots: an evaluation of felid attractants. Hystrix Ital J Mammal 25(2):113-116

Crooks KR (2002) Relative sensitivities of mammalian carnivores to habitat fragmentation. Conserv Biol 16(2):488-502

Elmhagen B, Rushton SP (2007) Trophic control of mesopredators in terrestrial ecosystems: top-down or bottom-up? Ecol Lett 10(3):197-206

Estes JA, Terborgh J, Brashares JS, Power ME, Berger J, Bond WJ, Carpenter SR et al (2011) Trophic downgrading of planet Earth. Science 333:301-306

Fagan ME, DeFries RS, Sesnie SE, Arroyo JP, Walker W, Soto C, Chazdon RL, Sanchun A (2013) Land cover dynamics following a deforestation ban in northern Costa Rica. Environ Res Lett 8(3):034017

Fahrig L (2003) Effects of habitat fragmentation on biodiversity. Annu Rev Ecol Syst 34:487-515

Garrott RA, White PJ, Vanderbilt White CA (1993) Overabundance: an issue for conservation biologists? Conserv Biol 7(4):946-949

Guariguata MR, Arias- Le Claire H, Jones G (2002) Tree seed fate in a logged and fragmented forest landscape, Northeastern Costa Rica. Biotropica 34(3):405-415

Haddad NM (2015) Corridors for people, corridors for nature. Science 350(6265):1166-1167

Hines JE (2006) PRESENCE-Software to estimate patch occupancy and related parameters. USGS-PWRC. http://www.mbr-pwrc.usgs.gov/software/presence.html

Johns A (1985) Selective logging and wildlife conservation in tropical rain forest: problems and recommendations. Biol Conserv 31:355-375

Laurance WF, Lovejoy TE, Vasconcelos HL, Bruna EM, Didham RK, Stouffer PC, Gascon C, Bierregaard RO, Laurance S, Sampaio E (2002) Ecosystem decay of Amazonian forests fragments: a 22 year investigation. Conserv Biol 16:605-618

Layman CA, Giery ST, Buhler S, Rossi R, Penland T, Henson MN, Bogdanoff AK, Cove MV, Irizarry AD, Schalk CM, Archer SK (2015) A primer on the history of food web ecology: fundamental contributions of fourteen researchers. Food Webs 4:14-24

Linkie M, Dinata Y, Nugroho A, Haidir I (2007) Estimating occupancy of a data deficient mammalian species living in tropical rainforests: Sun bears in the Kerinci Seblat region, Sumatra. Biol Conserv 137(1):20-27

MacKenzie DI, Nichols JD, Lachman GB, Droege S, Royle JA, Langtimm CA (2002) Estimating site occupancy rates when detection probabilities are less than one. Ecology 83:2248-2255 
MacKenzie D, Nichols JD, Royle JA, Pollock K, Bailey L, Hines J (2006) Occupancy Estimation and modeling: Inferring patterns and dynamics of species occupancy. Academic Press, New York

Maffei L, Cuéllar E, Noss AJ (2002) Uso de trampas-cámara para la evaluación de mamíferos en el ecotono chaco-chiquitanía. Rev Bol Ecol 11:55-65

Michalski F, Peres C (2007) Disturbance-mediated mammal persistence and abundance-area relationships in amazonian forest fragments. Conserv Biol 21(6):1626-1640

Murcia C (1995) Edge effect in fragmented forest: implications for conservation. TREE 10(2):58-62

Myers N, Mittermeier RA, Mittermeier CG, Da Fonseca GA, Kent J (2000) Biodiversity hotspots for conservation priorities. Nature 403(6772):853-858

Noss RF, Quigley HB, Hornocker MG, Merrill T, Paquet PC (1996) Conservation biology and carnivore conservation in the Rocky Mountains. Wildl Res 10(4):949-963

Pardini R, Marques de Souza S, Braga-Neto R, Metzger J (2005) The role of forest structure, fragment size and corridors in maintaining small mammal abundance and diversity in an Atlantic forest landscape. Biol Conserv 124:253-266

Pardo L, Payán E (2015) Mamíferos de un agropaisaje de palma de aceite en las sabanas inundables de Orocué, Casanare, Colombia. Biota Colomb 16(1):54-66

Pearce DW, Putz F, Vanclay JK (2003) Sustainable forestry in the tropics: panacea or folly? For Ecol Manag 172(2-3):229-247

Ritchie EG, Johnson CN (2009) Predator interactions, mesopredator release and biodiversity conservation. Ecol Lett 12:982-998

Rodríguez-Herrera B, Chinchilla F, May-collado L (2002) Lista de especies, endemismo y conservación de los de mamíferos de Costa Rica. Revista Mexicana de Mastozoología 6:19-41

Roemer GW, Gompper ME, Valkenburgh BV (2009) The ecological role of the mammalian mesopredator. Bioscience 59(2):165-173

Rosenberg DK, Noon BR, Meslow EC (1997). Biological corridors: form, function, and efficacy. BioScience 47(10):677-687

Ruiz-Gutiérrez V, Zipkin EF, Dhondt AA (2010) Occupancy dynamics in a tropical bird community: unexpectedly high forest use by birds classified as non-forest species. J Appl Ecol 47(3):621-630

Salom-Pérez R, Carrillo E, Sáenz JC, Mora JM (2007) Critical condition of the jaguar Panthera onca population in Corcovado National Park, Costa Rica. Oryx 41(01):51-56

Schank C, Mendoza E, Vettorazzi MJG, Cove MV, Jordan CA, O`Farrill G, Meyer N, Lizcano DJ, Estrada N, Poot C, Leonardo R (2015) Integrating current range-wide occurrence data with species distribution models to map the potential distribution of Baird's Tapir. Tapir Conserv 24(33):15-25

Schipper J, Chanson JS, Chiozza F, Cox NA, Hoffmann M, Katariya V et al (2008) The status of the world's land and marine mammals: diversity, threat, and knowledge. Science 322:225-230

Soulé M, Boger D, Alberts A, Wright J, Sorice M, Hill S (1988) Reconstructed dynamics of rapid extinctions of chaparral-requiring birds in urban habitat islands. Conserv Biol 2(1):75-92

Terborgh J (1988) The big thing that run the world: a sequel to E.O. Wilson. Conserv Biol 2:402-403

Terborgh J (1992) Maintenance of diversity in tropical forests. Biotropica 24(2):283-292

Thornton D, Zeller K, Rondinini C, Boitani L, Crooks KR, Burdett C, Rabinowitz A, Quigley A (2015). Assessing the umbrella value of a range-wide conservation network for jaguars (Panthera onca). Ecol Appl. doi:10.1890/15-0602.1

Tobler MW, Carrillo-Percastegui SE, Leite Pitman R, Mares R, Powell G (2008) An evaluation of camera traps for inventorying large and medium sized terrestrial rainforest mammals. Anim Conserv 11:169-178

Wainwright M (2002) The natural history of Costa Rican mammals. Zona Tropical, San Jose

Woodroffe R, Ginsberg J (1998) Edge effects and the extinction of populations inside protected areas. Science 280:2126-2128 